Supporting information for

\title{
General Synthetic Route to High Quality Colloidal III-V Semiconductor Quantum Dots Based on Pnictogen Chlorides
}

Tianshuo Zhao ${ }^{\dagger \#}$ Nuri Oh, ${ }^{\ddagger} \| \#$ Davit Jishkariani, ${ }^{\perp}$ Mingliang Zhang, ${ }^{\ddagger}$ Han Wang, ${ }^{\ddagger}$ Na Li,${ }^{\nabla}$ Jennifer D. Lee, ${ }^{\S}$

Chenjie Zeng, ${ }^{\S}$ Manisha Muduli, ${ }^{\dagger}$ Hak-Jong Choi, ${ }^{\dagger}$ Dong Su, ${ }^{\nabla}$ Christopher B. Murray, ${ }^{* \downarrow \S}$ and Cherie R. Kagan ${ }^{* \dagger \downarrow}$

${ }^{\dagger}$ Department of Materials Science and Engineering, ${ }^{\star}$ Department of Electrical and Systems Engineering, ${ }^{\S}$ Department of Chemistry, University of Pennsylvania, Philadelphia, Pennsylvania 19104, United States

${ }^{\perp}$ Chemical and Nanoparticle Synthesis Core (CNSC), Perelman School of Medicine, University of Pennsylvania, Philadelphia, Pennsylvania 19104, United States

"Division of Materials Science and Engineering, Hanyang University, Seoul 04763, Republic of Korea

${ }^{\nabla}$ Center for Functional Nanomaterials, Brookhaven National Laboratory, Upton, New York 11953, United States

* To whom correspondence should be addressed. E-mail: (C.B.M.) cbmurray@ sas.upenn.edu, (C.R.K.) kagan@ seas.upenn.edu 


\section{Chemicals}

Indium (III) chloride (anhydrous, 99.999\%), arsenic (III) chloride (99.999\%) and antimony (III) chloride (99.999\%) are purchased from Strem Chemicals. Oleylamine (OLAM, 70\%), lithium triethylborohydride ( $\mathrm{LiEt}_{3} \mathrm{BH}$, superhydride, 1.0 M solution in THF), dioctyl ether (DOE), tetrachloroethylene (TCE, anhydrous, $\geq 99 \%$ ), acetonitrile (anhydrous, 99.8\%), toluene (anhydrous 99.8\%), methanol (anhydrous, 99.8\%), formamide (>99.5\%), N,N-dimethylformamide (anhydrous, 99.8\%), sodium sulfide and sodium azide (>99.5\%) are purchased from Sigma-Aldrich. All chemicals are used as received.

\section{III-V Quantum Dot Purification}

We purify the reaction crude to extract III-V QD products in a nitrogen filled glovebox. $30 \mathrm{~mL}$ of toluene is added to the reaction crude, which is subsequently divided into two centrifuge tubes. For InSb QDs, $1 \mathrm{~mL}$ of pre-degassed oleic acid is added to each tube to improve colloidal stability. Then the dispersion is centrifuged at 8000 r.p.m for 5 min to remove insoluble by-products through precipitation. $4 \mathrm{~mL}$ of acetonitrile is slowly added to each supernatant to allow the larger QDs to aggregate. These aggregates form pellets after another centrifugation step and are discarded. Again, another $4 \mathrm{~mL}$ of acetonitrile is added slowly and the dispersion is centrifuged to remove larger particles and further narrow the QD size distribution. Finally, the rest of the QDs are completely precipitated by $3 \mathrm{~mL}$ of acetonitrile, collected after centrifugation, and redispersed in toluene at $15 \mathrm{mg} / \mathrm{mL}$.

\section{Characterization of III-V QDs}

UV-Vis absorption and photoluminescence. As synthesized III-V QDs are redispersed in TCE for absorption and photoluminescence measurements using an Agilent Cary 5000 and Edinburgh Instruments FLS1000 fluorescence spectrometer, respectively.

X-ray diffraction (XRD). QD dispersions are drop-cast on $\mathrm{Si}$ wafers for powder XRD measurements. XRD measurements are performed on a Rigaku SmartLab diffractometer with $\mathrm{Cu} \mathrm{K} \alpha$ radiation $(40 \mathrm{kV}$ and $30 \mathrm{~mA})$ using a $\theta-2 \theta$ geometry.

Transmission electron microscopy (TEM) and high-resolution TEM (HR-TEM). TEM samples are prepared by drop-casting diluted QD dispersions onto 300 mesh carbon-coated copper TEM grids and allowed to dry. TEM images of III-V QDs are taken by a JEOL JEM1400 TEM operating at $120 \mathrm{kV}$. HR-TEM is performed on a JEOL 2100F TEM equipped with a field-emission electron gun operated at $200 \mathrm{kV}$.

The elemental composition of III-V QDs are determined by Inductively Coupled Plasma-Optical Emission spectrometry (ICP-OES) and Energy-dispersive X-ray spectroscopy (EDS). The ICP-OES measurements are performed on a Spectro Genesis spectrometer with a concentric nebulizer, and EDS measurements are carried out with an Oxford Instruments energy-dispersive spectrometer in a FEI Quanta 600 ESEM.

Nuclear magnetic resonance (NMR). 1H NMR (500 MHz) spectra are recorded on Bruker UNI500 or BIODRX500 NMR spectrometer. Chemical shifts $(\delta)$ are reported in ppm while coupling constants $(J)$ are reported in Hertz $(\mathrm{Hz})$. The multiplicity of signals is described as "s" (singlet), "d" (doublet), " $\mathrm{t}$ " (triplet), "q" (quartet), and "m" (multiplet). All spectra are recorded in deuterated chloroform and referenced using solvent residual signals $\left(\mathrm{CDCl}_{3}: 1 \mathrm{H}, \delta 7.26 \mathrm{ppm}\right)$. 
Matrix-Assisted Laser Desorption/ionization Time of Flight (MALDI-TOF) Mass Spectroscopy is performed on a Bruker Ultraflex III (MALDI-TOF) mass spectrometer using dithranol as matrix. For analysis, materials are mixed with dithranol and sodium acetate at a 2:1:1 ratio in THF. The resulting mixture is deposited on a MALDI plate and allowed to dry before analyzing.

X-ray photoelectron spectroscopy (XPS). Drop-cast III-V QD films are transferred air-free from a glovebox to the instrument chamber with a sealed vessel. Samples are measured by a Physical Electronics Versa Probe 5000 Spectrometer.

Fourier-transform infrared spectroscopy (FTIR). III-V QD films are measured by a Nicolet 6700 (Thermo Scientific) spectrometer with a mercury cadmium telluride detector at normal incidence. The FTIR absorbance is normalized by the absorption peak intensity in the UV-Vis-NIR spectrum of the same sample.

\section{Additional Figures}
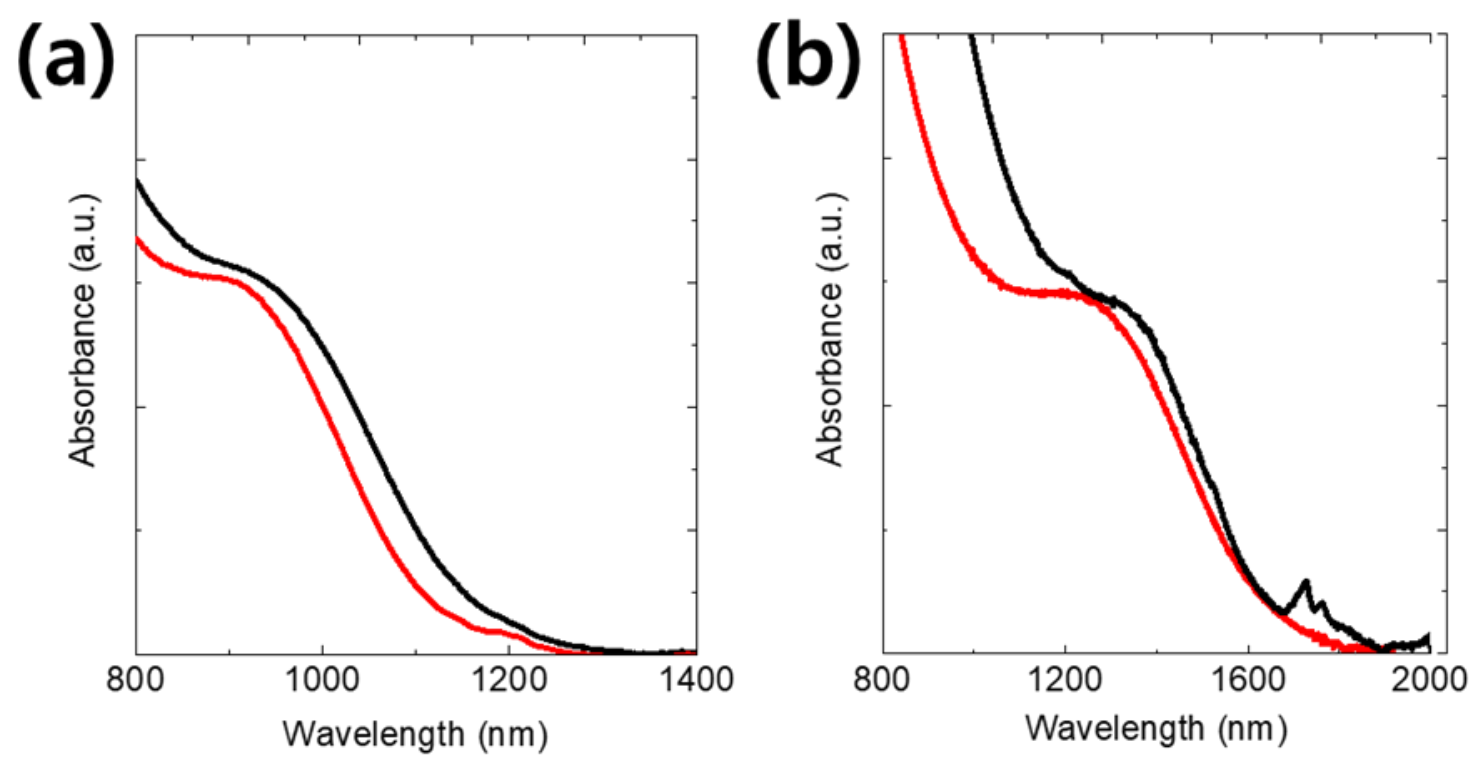

Figure S1. UV-Vis absorption spectra of (a) InAs and (b) InSb QDs synthesized at $300{ }^{\circ} \mathrm{C}$ before (black) and after (red) the size selection process. 
(a)

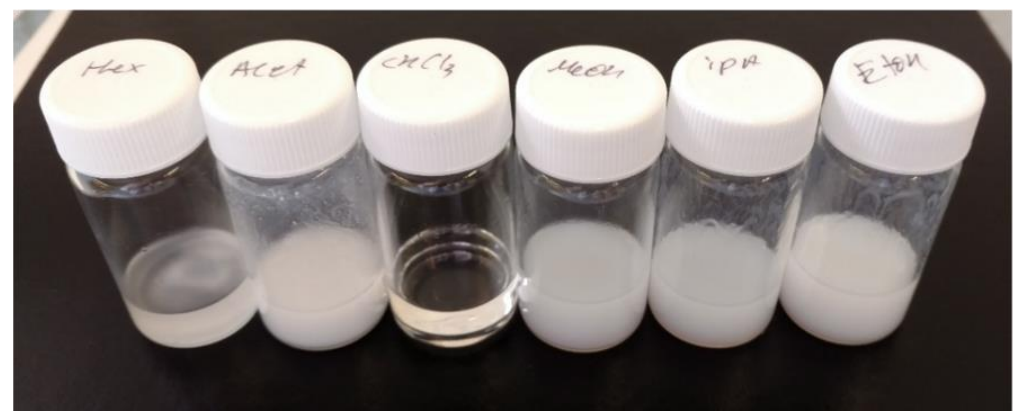

(b)

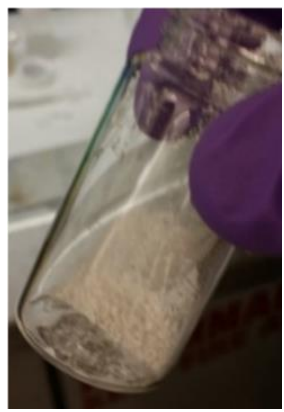

Figure S2. Photograph of (a) $\mathrm{SbCl}_{3}$-OLAM precursor solutions after adding hexane, acetone, chloroform, methanol, isopropanol and ethanol (from left to right) and (b) a powder of a $\mathrm{SbCl}_{3}$-OLAM precursor precipitate isolated and dried from the turbid mixture of $\mathrm{SbCl}_{3}-\mathrm{OLAM}$ and methanol.

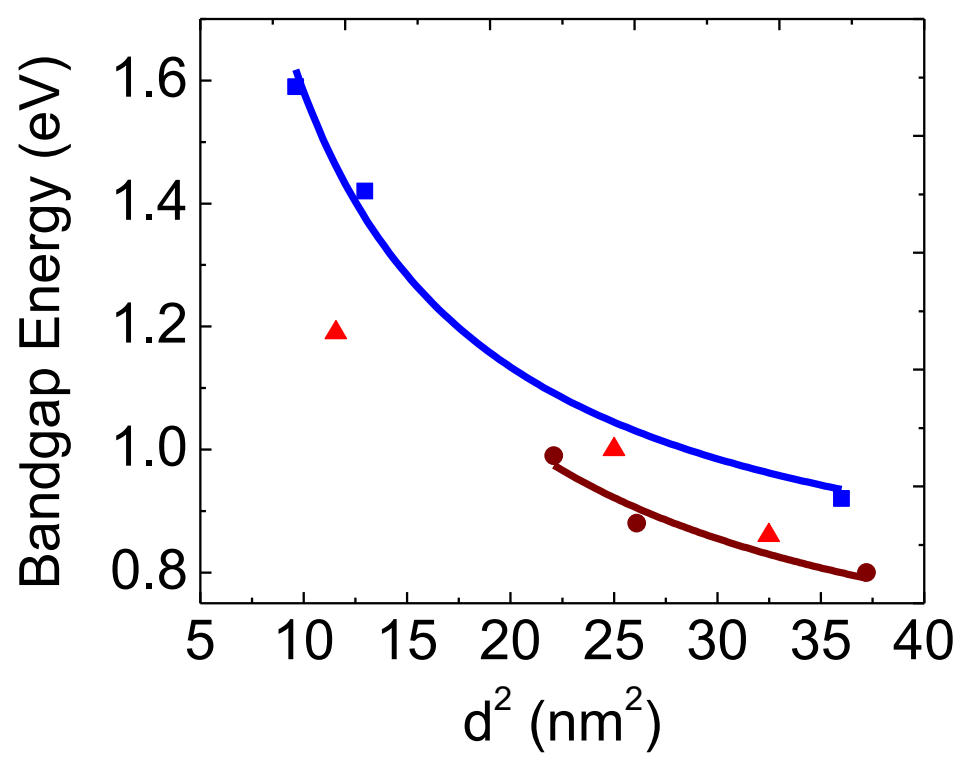

Figure S3. Size-dependent bandgap energies of InAs (blue squares), InSb (brown dots) and $\operatorname{InAs}_{1-\mathrm{x}} \mathrm{Sb}_{\mathrm{x}}$ (red triangles) QDs as a function of their diameter $d$. 

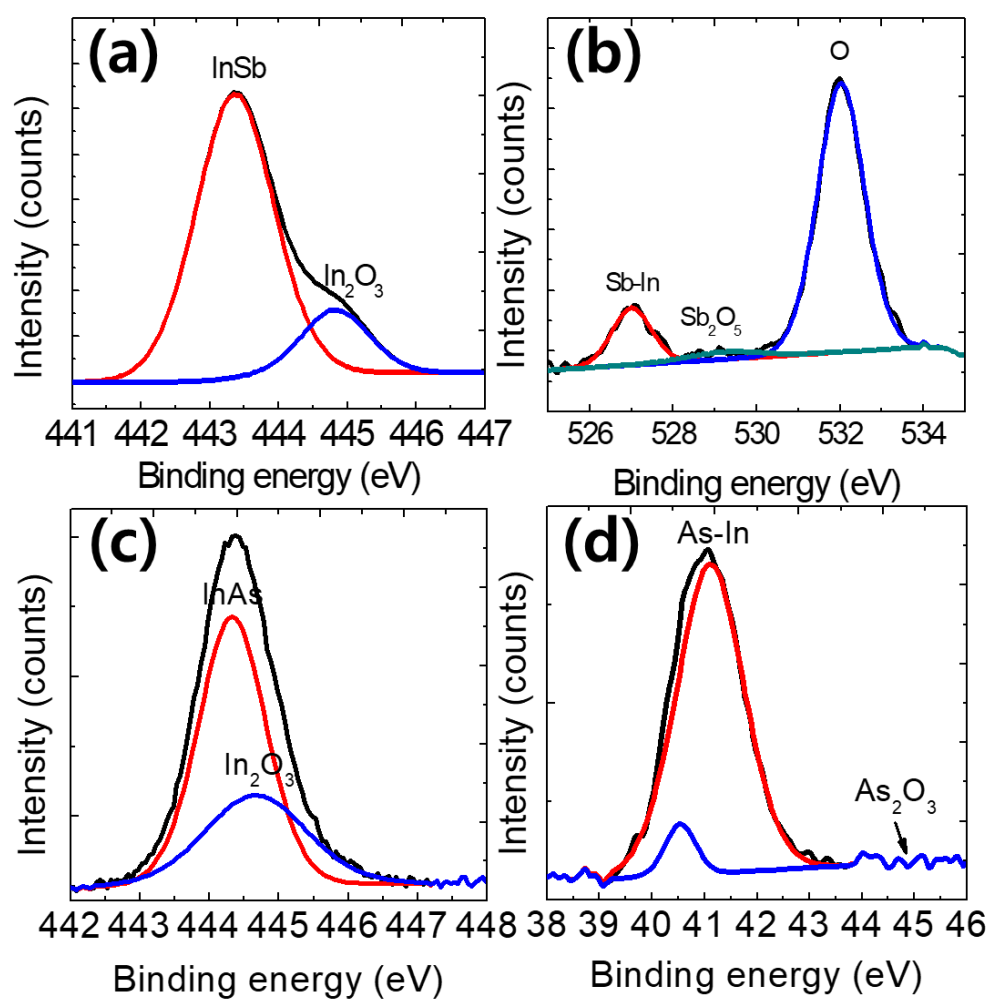

Figure S4. XPS core-level spectra of InSb QDs in the (a) In 3d and (b) Sb 3d region, and InAs QDs in the (c) In 3d and (d) As 3d regions. Peak assignments are based on the National Institute of Standards and Technology (NIST) Standard Reference Database 20, Version 4.1. 

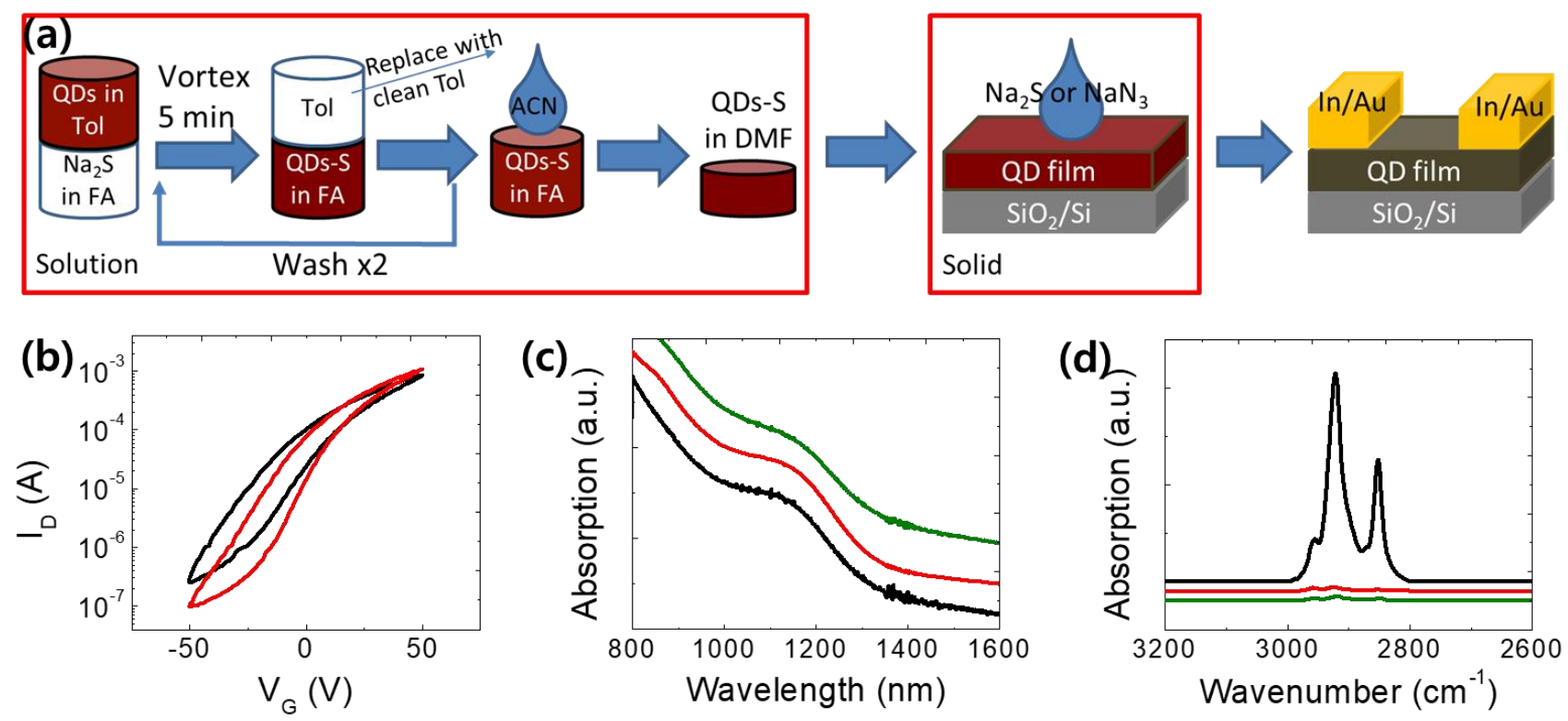

(e)

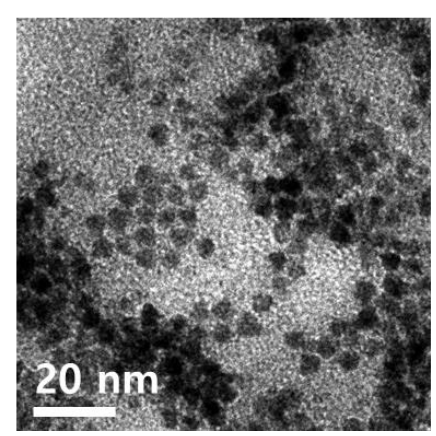

(f)

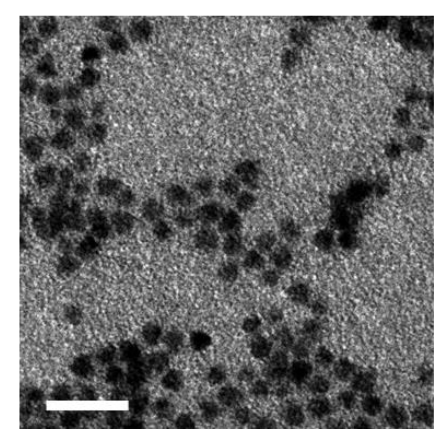

(g)

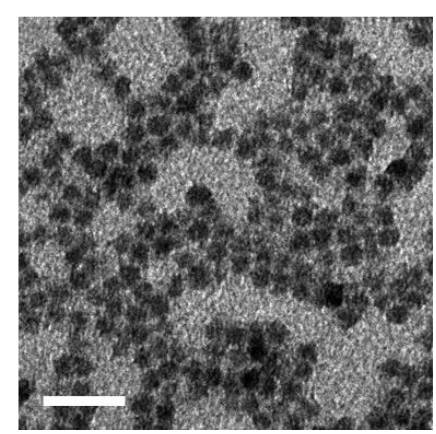

Figure S5. (a) Schematics of the hybrid ligand exchange process for making FETs, which consists of a solution ligand exchange with $\mathrm{Na}_{2} \mathrm{~S}$, a solid-state ligand exchange with $\mathrm{Na}_{2} \mathrm{~S}$ or $\mathrm{NaN}_{3}$, and deposition of $\mathrm{In} / \mathrm{Au}$ electrodes. (b) Transfer characteristics of InAs QD FETs with $\mathrm{Na}_{2} \mathrm{~S}$ solution and solid-state hybrid ligand exchange (black) and $\mathrm{Na}_{2} \mathrm{~S}$ solution and $\mathrm{NaN}_{3}$ solid-state hybrid ligand exchange (red). (c) UV-Vis-NIR absorption spectra and (d) FTIR of InAs QD films with original OLAM ligands (black), after $\mathrm{Na}_{2} \mathrm{~S}$ solution ligand exchange (red), and $\mathrm{Na}_{2} \mathrm{~S}$ solution and $\mathrm{NaN}_{3}$ solid-state hybrid exchange (green). (e) to (g) TEM images of InAs QDs after $\mathrm{Na}_{2} \mathrm{~S}$ solid-state, $\mathrm{Na}_{2} \mathrm{~S}$ solution, and $\mathrm{Na}_{2} \mathrm{~S}$ solution and $\mathrm{NaN}_{3}$ solid-state hybrid ligand exchange, respectively. 
(a)

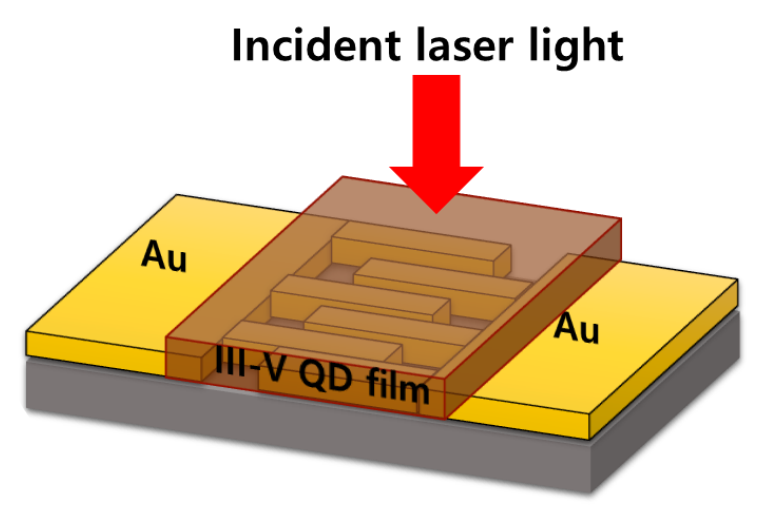

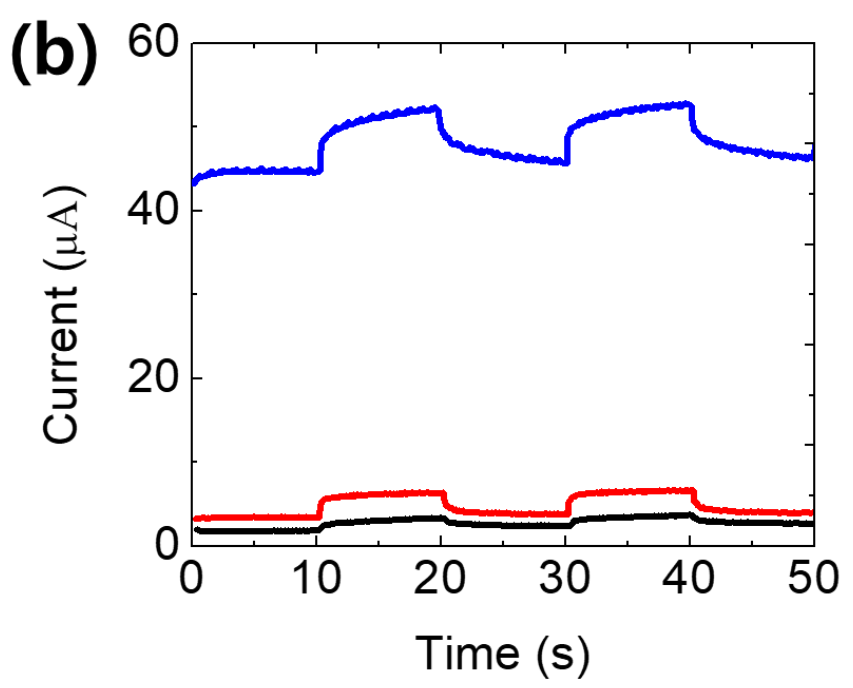

Figure S6. (a) Schematic of a QD photoconductor. Interdigitated, bottom Au electrodes with a 10- $\mu \mathrm{m}$ spacing are patterned by photolithography. (b) Photoresponse of InAs QD photoconductors under an electric field of $2 \times 10^{3} \mathrm{~V} / \mathrm{cm}$ with $\mathrm{Na}_{2} \mathrm{~S}$ solid-state (black), $\mathrm{Na}_{2} \mathrm{~S}$ solution (red) and $\mathrm{Na}_{2} \mathrm{~S}$ solution and $\mathrm{NaN}_{3}$ solid-state hybrid (blue) ligand exchange excited by a laser source at $1100 \mathrm{~nm}$ and $7.6 \mathrm{~mW} / \mathrm{cm}^{2}$.
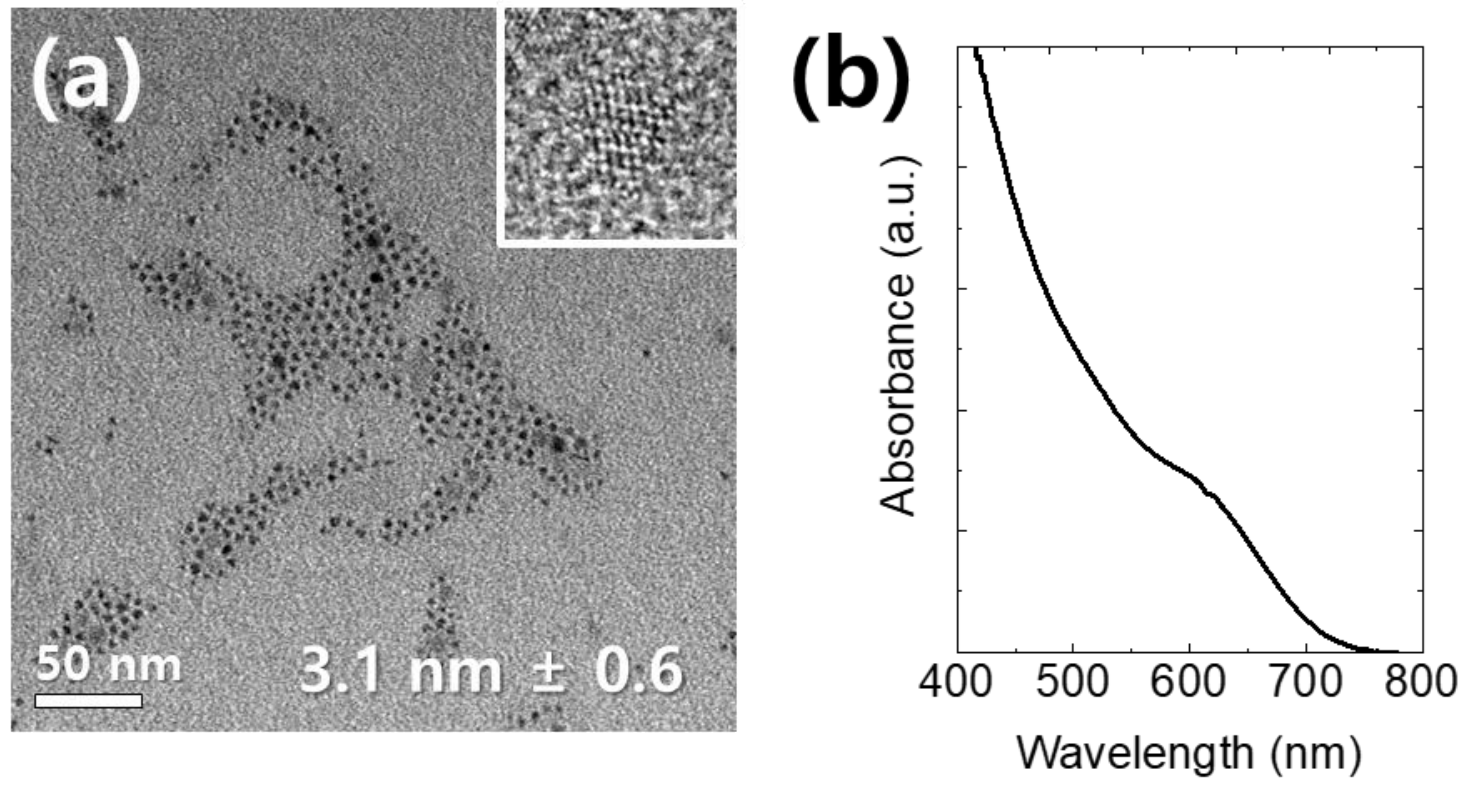

Figure S7. Preliminary results showing (a) low and high resolution (inset) TEM images and (b) absorption spectrum of InP QDs synthesized by co-reducing $\mathrm{InCl}_{3}$-OLAM and $\mathrm{PCl}_{3}$-OLAM with superhydride. 


\section{Copies of ${ }^{1} \mathbf{H}$ spectra}

Room temperature NMR spectra of neat OLAM, $\mathrm{AsCl}_{3}-\mathrm{OLAM}, \mathrm{SbCl}_{3}$-OLAM and $\mathrm{InCl}_{3}$-OLAM precursors, OLAM-capped InAs QDs, OA, and OA capped InSb QDs from top to the bottom.






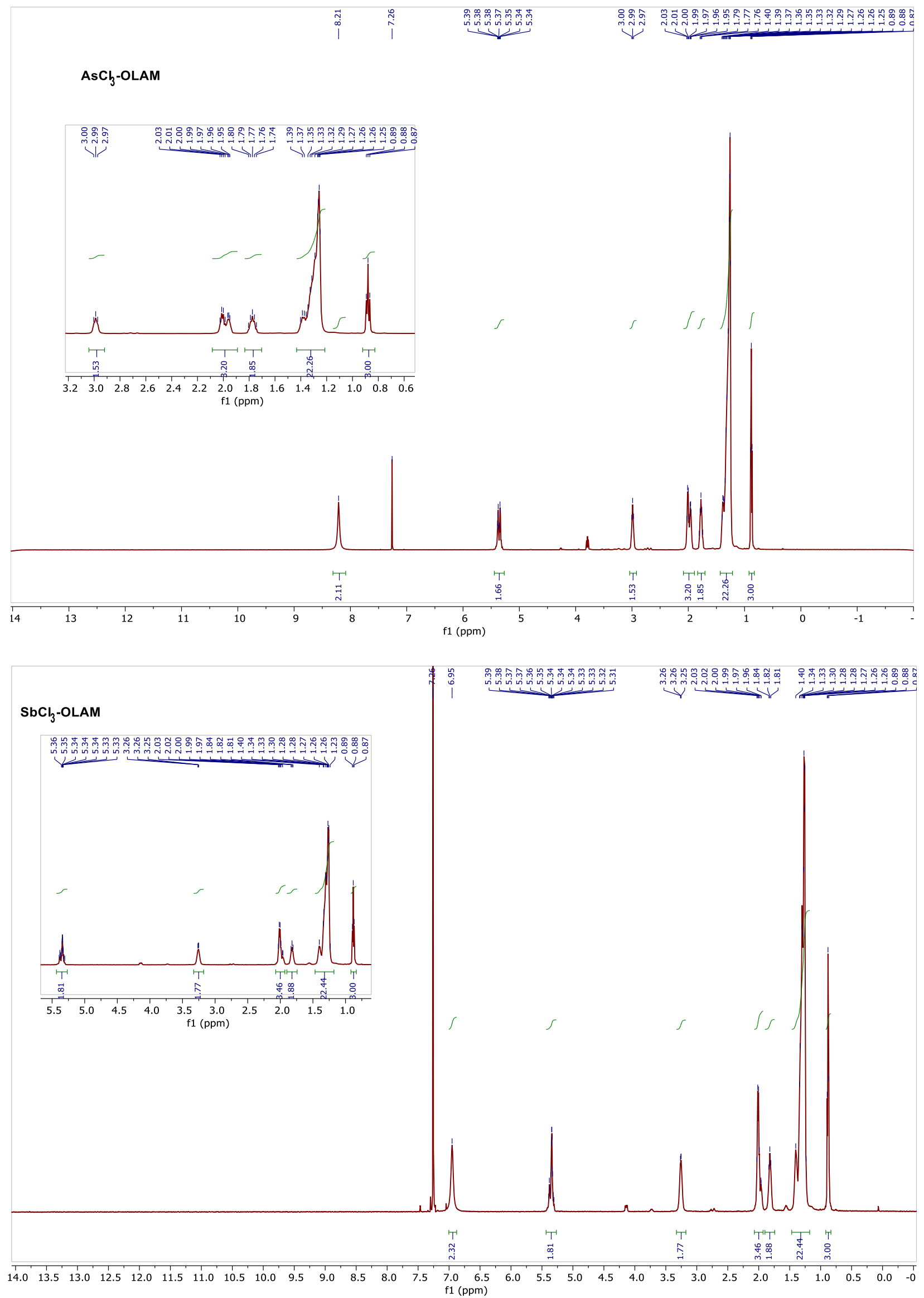




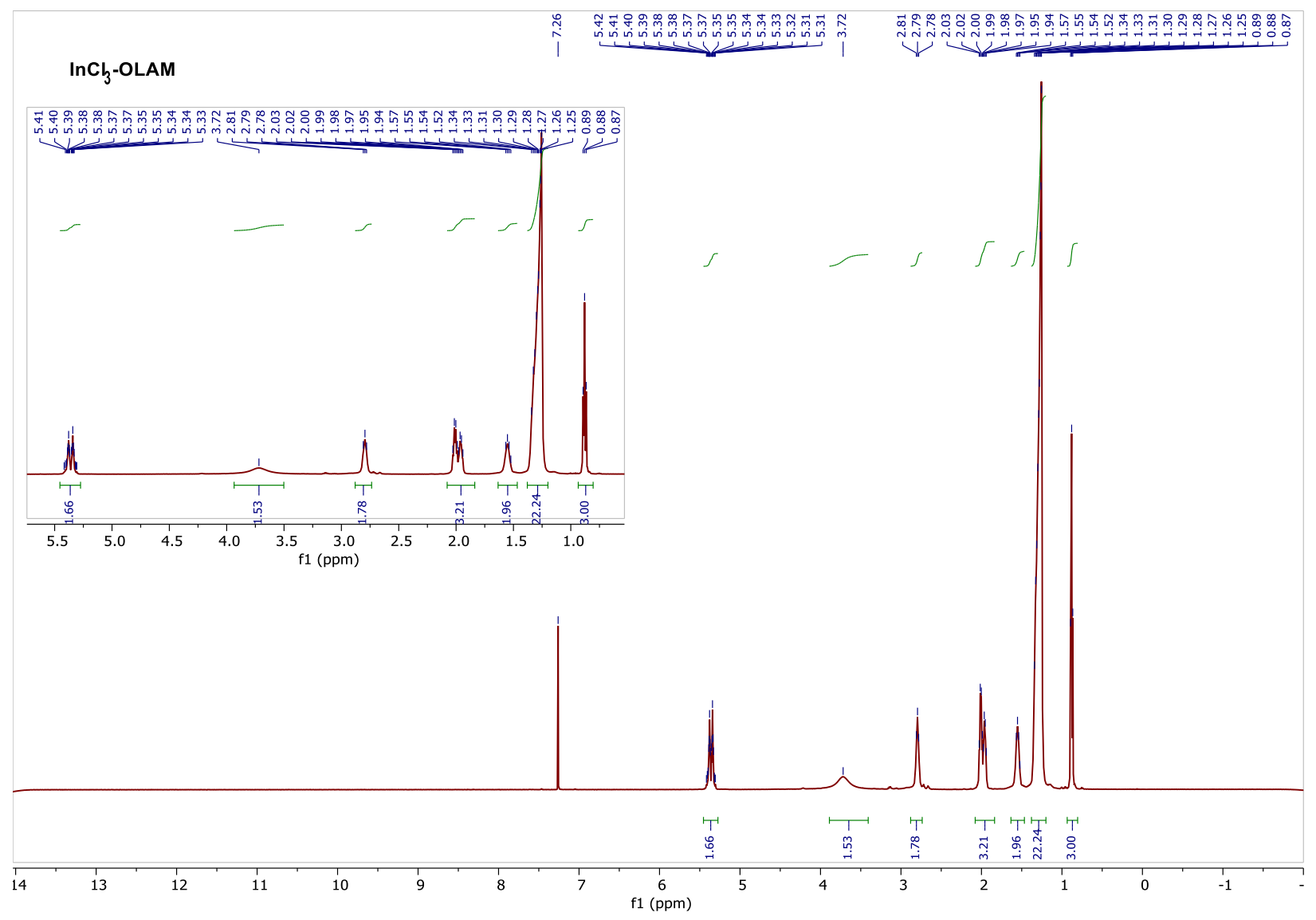









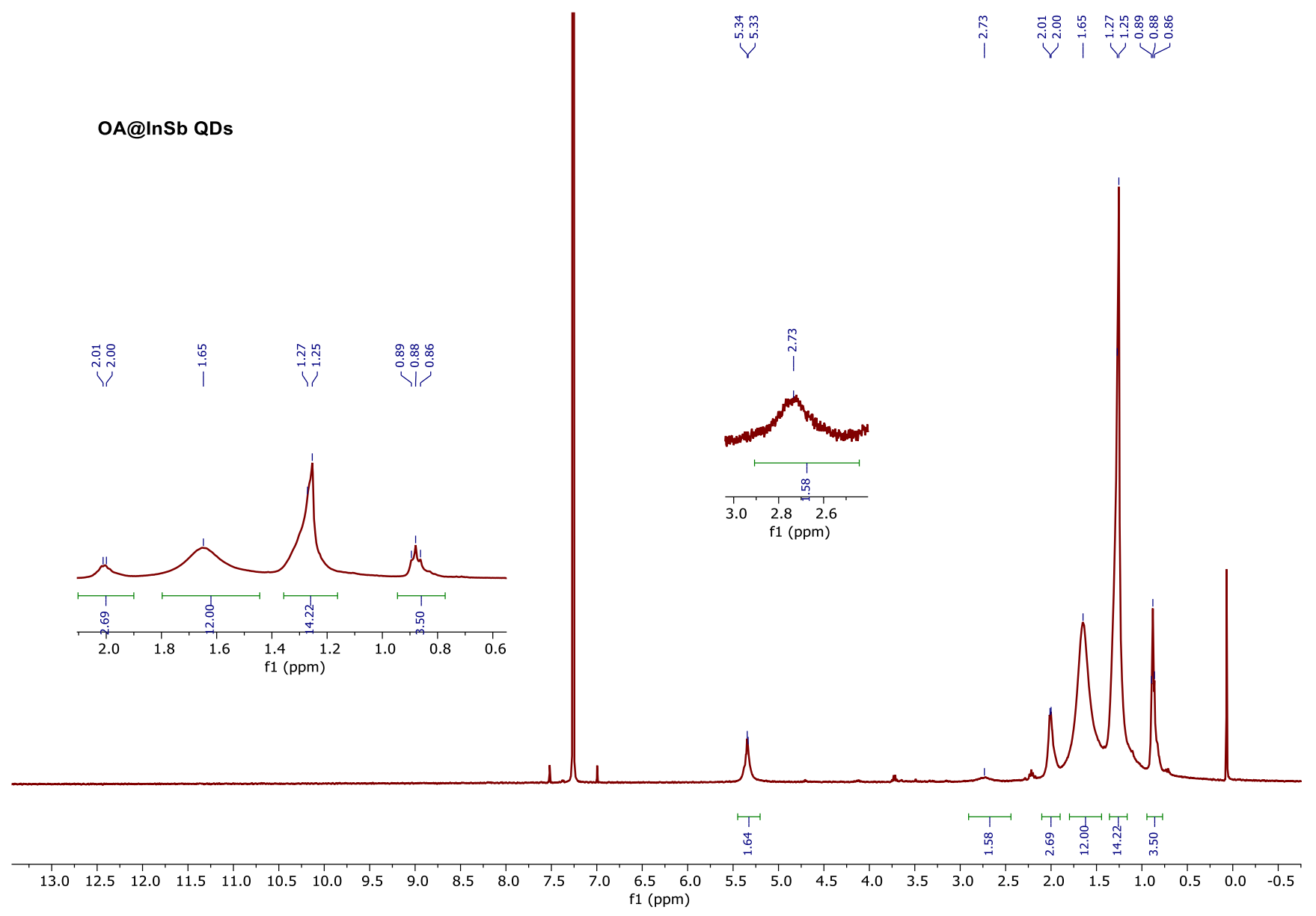

\section{6. ${ }^{1} \mathrm{H}$ NMR and MALDI-TOF data of precursor mixtures.}

Oleylamine (OLAM). ${ }^{1} \mathrm{H}$ NMR (500 MHz, $\left.\mathrm{CDCl}_{3}\right) \delta 5.46-5.27(\mathrm{~m}, 2 \mathrm{H}), 2.68(\mathrm{t}, J=7.0 \mathrm{~Hz}, 2 \mathrm{H}), 2.07-1.98(\mathrm{~m}, 2 \mathrm{H})$, $1.98-1.90(\mathrm{~m}, 1 \mathrm{H}), 1.44$ (p, $J=7.1 \mathrm{~Hz}, 2 \mathrm{H}), 1.39-1.19(\mathrm{~m}, 25 \mathrm{H}), 0.88(\mathrm{t}, J=6.8 \mathrm{~Hz}, 3 \mathrm{H})$.

OLAM + AsCl3. ${ }^{1} \mathrm{H}$ NMR $\left(500 \mathrm{MHz}, \mathrm{CDCl}_{3}\right) \delta 5.44-5.27(\mathrm{~m}, 2 \mathrm{H}), 2.99(\mathrm{t}, J=7.7 \mathrm{~Hz}, 2 \mathrm{H}), 2.09-1.89(\mathrm{~m}, 4 \mathrm{H}), 1.77(\mathrm{p}$, $J=7.6 \mathrm{~Hz}, 2 \mathrm{H}), 1.43-1.21(\mathrm{~m}, 22 \mathrm{H}), 0.88(\mathrm{t}, J=6.8 \mathrm{~Hz}, 3 \mathrm{H})$. MALDI-TOF $(\mathrm{m} / \mathrm{z})$ : [M+Na] $]^{+}$calcd. for $\mathrm{C}_{54} \mathrm{H}_{109} \mathrm{~N}_{3} \mathrm{AsNa}$, 896.7657; found: 896.203 .

OLAM + SbCl3. ${ }^{1} \mathrm{H}$ NMR $\left(500 \mathrm{MHz}, \mathrm{CDCl}_{3}\right) \delta 5.43-5.27(\mathrm{~m}, 2 \mathrm{H}), 3.33-3.18(\mathrm{~m}, 2 \mathrm{H}), 2.07-1.93(\mathrm{~m}, 3 \mathrm{H}), 1.90-1.74$ $(\mathrm{m}, 2 \mathrm{H}), 1.47-1.18(\mathrm{~m}, 22 \mathrm{H}), 0.88(\mathrm{t}, J=6.8 \mathrm{~Hz}, 3 \mathrm{H})$. MALDI-TOF $(\mathrm{m} / \mathrm{z}):[\mathrm{M}+\mathrm{H}]^{+}$calcd. for $\mathrm{C}_{54} \mathrm{H}_{109} \mathrm{~N}_{3} \mathrm{Sb}, 920.7660$; found: 920.520 .

OLAM + InCl3. ${ }^{1} \mathrm{H}$ NMR $\left(500 \mathrm{MHz}, \mathrm{CDCl}_{3}\right) \delta 5.45-5.27(\mathrm{~m}, 2 \mathrm{H}), 3.72(\mathrm{~s}, 1 \mathrm{H}), 2.88-2.74(\mathrm{~m}, 2 \mathrm{H}), 2.08-1.84(\mathrm{~m}$, $3 \mathrm{H}), 1.63-1.47(\mathrm{~m}, 2 \mathrm{H}), 1.38-1.20(\mathrm{~m}, 22 \mathrm{H}), 0.88(\mathrm{t}, J=6.8 \mathrm{~Hz}, 3 \mathrm{H})$. MALDI-TOF $(\mathrm{m} / \mathrm{z}):[\mathrm{M}+\mathrm{H}]^{+}$calcd. for $\mathrm{C}_{54} \mathrm{H}_{109} \mathrm{~N}_{3} \mathrm{In}, 914.7660$; found: 914.159. 
OLAM@InAs QD. ${ }^{1} \mathrm{H}$ NMR (500 MHz, $\left.\mathrm{CDCl}_{3}\right) \delta 5.41-5.39$ (m, 2H), $3.0-2.7$ (br. m, 2H), $2.09-1.91$ (m, $\left.2 \mathrm{H}\right), 1.69-$ $1.42(\mathrm{~m}, 6 \mathrm{H}), 1.38-1.13(\mathrm{~m}, 22 \mathrm{H}), 0.88(\mathrm{t}, \mathrm{J}=6.5 \mathrm{~Hz}, 3 \mathrm{H})$.

Oleic acid (OA). ${ }^{1} \mathrm{H}$ NMR $\left(400 \mathrm{MHz}, \mathrm{CDCl}_{3}\right) \delta 5.43-5.26(\mathrm{~m}, 2 \mathrm{H}), 2.35(\mathrm{t}, J=7.5 \mathrm{~Hz}, 2 \mathrm{H}), 2.10-1.93(\mathrm{~m}, 4 \mathrm{H}), 1.63(\mathrm{p}$, $J=7.3 \mathrm{~Hz}, 2 \mathrm{H}), 1.42-1.18(\mathrm{~m}, 20 \mathrm{H}), 0.88(\mathrm{t}, J=6.8 \mathrm{~Hz}, 3 \mathrm{H})$.

OA@InSb QD. ${ }^{1} \mathrm{H}$ NMR $\left(400 \mathrm{MHz}, \mathrm{CDCl}_{3}\right) \delta 5.45-5.20(\mathrm{~m}, 2 \mathrm{H}), 2.91-2.44(\mathrm{~m}, 2 \mathrm{H}), 2.10-1.90(\mathrm{~m}, 2 \mathrm{H}), 1.83-1.42$ $(\mathrm{m}, 12 \mathrm{H}), 1.39-1.09(\mathrm{~m}, 14 \mathrm{H}), 0.89(\mathrm{t}, J=6.0 \mathrm{~Hz}, 3 \mathrm{H})$. 